\title{
ABSORÇÃo DE ÁGUA E PROPRIEDADES ESPUMANTES DE FARINHAS EXTRUSADAS DE TRIGO E SOJA ${ }^{1}$
}

\author{
Sin H. WANG ${ }^{2, *}$, Geisa O. ROCHA ${ }^{2}$, Talita P. NASCIMENTO2 ${ }^{2}$, José L.R. ASCHERI ${ }^{3}$
}

\section{RESUMO}

Com o objetivo de verificar a possibilidade do uso de farinha extrusada de trigo e soja para bolo esponja, foram estudadas absorção de água (AA) e propriedades espumantes destas farinhas, as quais foram, anteriormente, extrusadas em três velocidades de rotação de parafuso (VRP) e três temperaturas do canhão (TC), usando-se três níveis de umidade. AA, expansão de espuma (EE) e estabilidade de espuma aumentaram, à medida que se aumentavam a VRP e a TC em 23\% de umidade. Contudo, em 26 e $29 \%$ de umidade, o maior valor da AA e da estabilidade de espuma foram obtidos em $150 \mathrm{rpm}$ a $90^{\circ} \mathrm{C}$. EE aumentou com o aumento da VRP em $80^{\circ} \mathrm{C}$, mas em 90 e $100^{\circ} \mathrm{C}$, os maiores valores foram verificados em $150 \mathrm{rpm}$. Sendo assim, a farinha mista com $23 \%$ de umidade, extrusada em $180 \mathrm{rpm}$ a $100^{\circ} \mathrm{C}$, bem como aquela com $26 \%$ de umidade, extrusada em $150 \mathrm{rpm}$ a $90^{\circ} \mathrm{C}$, são recomendadas para o uso em bolo esponja.

Palavras-chave: farinha pré-cozida, mistura de trigo e soja, propriedades tecnológicas.

\section{SUMMARY}

WATER ABSORPTION AND WHIPPING PROPERTIES OF EXTRUSION-COOKED WHEAT-SOYBEAN FLOURS. In order to verify the possibility of use of the extrusion-cooked wheat-soybean flour for sponge cake, water absorption (WA) and whipping properties of these flours were studied, which were, previously, extruded in three speeds screw rotation (SSR) and three barrel temperatures (BT), being used three moisture levels. WA, expansion of foam (EF) and stability of foam (SF) increased as increased SSR and BT at $23 \%$ moisture. However, at 26 and $29 \%$ moisture, the largest values of WA and of SF were obtained in $150 \mathrm{rpm}$ at $90^{\circ} \mathrm{C}$. $\mathrm{EF}$ increased as SSR increased at $80^{\circ} \mathrm{C}$, but at 90 and $100^{\circ} \mathrm{C}$, the largest values were verified in $150 \mathrm{rpm}$. In conclusion, the mixed flour with $23 \%$ moisture, extruded in $180 \mathrm{rpm}$ at $100^{\circ} \mathrm{C}$, as well as that one with $26 \%$ moisture, extruded in $150 \mathrm{rpm}$ at $90^{\circ} \mathrm{C}$, are recommended for use in sponge cake.

Keywords: pre-cooked flour, wheat-soybean mixture, technological properties.

\section{1 - INTRODUÇÃO}

A soja tem sido reconhecida como excelente fonte de proteína para fortificar produtos de trigo, através da complementação mútua de aminoácidos e do aumento no conteúdo de proteínas totais [2]. Entretanto, a aceitação de um ingrediente protéico pela indústria de alimentos não se deve apenas às suas qualidades nutricionais, mas também às suas propriedades funcionais, as quais definem aplicações comerciais [7].

Vários estudos têm demonstrado a contribuição de soja na melhoria de certas propriedades funcionais em sistemas alimentares. As proteínas de soja são consideradas bons agentes de aeração, tendo propriedades espumantes adequadas e podendo ser utilizadas, funcionalmente, em manufatura de suflês, suspiro, doces congelados, coberturas de bolos, sorvetes e outros [20].

\footnotetext{
${ }^{1}$ Recebido para publicação em .8/11/2005 Aceito para publicação em 28/4/2006 (001634)

${ }^{2}$ Departamento de Economia Doméstica - ICHS, UFRRJ

BR-465, Km 47, CEP 23890-000, Seropédica (RJ)

E-mail:sin-hueiwang@bol.com.br; yzzaufrrj@hotmail.com; tpimenta1@ hotmail.com.

${ }^{3}$ Embrapa Agroindústria de Alimentos

Avenida das Américas, 29.501, CEP 23020-470 - Guaratiba, Rio de Janeiro (RJ)

E-mail: ascheri@ctaa.embrapa.br

*A quem a correspondência deve ser enviada
}

A extrusão termoplástica é definida como um processo contínuo no qual o trabalho mecânico é combinado com a ação do calor para gelatinizar o amido e desnaturar proteínas, plasticizando e reestruturando o material, para criar novas formas e texturas. A operação de extrusão é feita em extrusores. Extrusores de diferentes desenhos são utilizados na produção de alimentos pré-cozidos, proteínas vegetais texturizadas, bebidas instantâneas em pó, sopas instantâneas, alimentos infantis, snacks, etc. [14].

Além de possuir os benefícios usuais de um processo térmico convencional, a extrusão termoplástica oferece a possibilidade de melhorar as propriedades funcionais e diminuir a quantidade de materiais antinutricionais [3, 6, 17]. Segundo KIM \& ROTTIER [9], a farinha pré-cozida, obtida por extrusão de semolina com $30 \%$ de umidade a $60^{\circ} \mathrm{C}$, foi extremamente adequada para preparo de bolo esponja, por ter apresentado boas propriedades espumantes. WANG et al. [19] relataram que o aumento do nível de umidade e da temperatura do extrusor resultou num aumento da absorção de água da farinha extrusada de trigo e soja, o que pode ajudar a manter a umidade da massa de pizza, proporcionando a maciez de sua textura.

Considerando-se que não existe nenhum dado disponível na literatura sobre as modificações ocorridas na absorção de água e nas propriedades espumantes das farinhas de trigo e soja (90:10) extrusadas por diferentes 
velocidades de rotação de parafuso em diferentes combinações de umidade e temperatura do canhão, realizou-se o presente trabalho com o objetivo de otimizar o processo de extrusão para a obtenção de farinhas pré-cozidas adequadas para o uso em bolo esponja.

\section{2 - MATERIAL E MÉTODOS}

\section{1 - Matéria-prima}

As matérias-primas usadas para os estudos foram: a farinha de trigo, marca número um, adquirida no supermercado local, e grãos de soja Glycine max (L.) Merril, cultivar BRS-156, safra 2002, fornecidos pela Embrapa Soja, Londrina (PR).

\section{2 - Métodos}

A obtenção de farinhas extrusadas de trigo e soja e todas as análises que seguem foram feitas em duplicata.

\subsection{1 - Obtenção de farinha mista crua}

Os grãos de soja foram decorticados e branqueados, usando-se a metodologia de WANG et al. [17]. Em seguida, foram misturados com a farinha de trigo, na proporção de 10:90 (soja:trigo), em base seca, sendo acrescentada água, em diferentes níveis, e as misturas desintegradas, em moinho granulador de facas e martelos da marca Treu 7,5 CV modelo 112M989, com peneira de $2 \mathrm{~mm}$, para obtenção de farinhas mistas cruas de trigo e soja com 23 , 26 e $29 \%$ de umidade.

\subsection{2 - Composição centesimal aproximada}

Na farinha de trigo, nos grãos de soja integrais e decorticados, e na farinha mista crua de trigo e soja (90:10), foram realizadas as análises de umidade, extrato etéreo, proteína bruta e cinzas, segundo métodos de AACC [1] e de fibra bruta, conforme KAMER \& GINKEL [8].

\subsection{3 - Processo de extrusão e obtenção da farinha mista pré-cozida}

As farinhas mistas cruas de três níveis de umidade foram extrusadas em extrusor Brabender de rosca única, usando velocidade de alimentação constante de $3,6 \mathrm{Kg} \bullet \mathrm{h}^{-1}$, três velocidades de rotação de parafuso ( ${ }^{\circ}$ 3; 120,150 e $180 \mathrm{rpm}$ ) e matriz de lâmina com espessura de $1 \mathrm{~mm}$. Os perfis de temperatura do canhão do extrusor foram de $50^{\circ} \mathrm{C}$ constante na zona 1 e de 80,90 e $100^{\circ} \mathrm{C}$ nas zonas 2 e 3 . Os produtos extrusados foram designados nas seguintes seqüências: G23\%80, G23\%90, G23\%100, G26\%80, G26\%90, G26\%100, G29\%80, G29\%90, G29\%100. Em seguida, os produtos extrusados foram secados em estufa a $50^{\circ} \mathrm{C}$, com circulação de ar até peso constante com, aproximadamente, 7-8\% de umidade, sendo moídos em moinho de martelos Laboratory Mill 3600. As farinhas mistas extrusadas foram submetidas às subseqüentes análises, nas quais a farinha de trigo crua, e a farinha mista crua de trigo e soja (90:10), foram usadas como controle.

\subsection{4 - Absorção de água}

A absorção de água foi determinada, segundo o método descrito por SOSULSKI [15]. Pesou-se $5 \mathrm{~g}$ de amostra num tubo de centrífuga de $50 \mathrm{~mL}$ e adicionouse $30 \mathrm{~mL}$ de água destilada. Agitou-se a amostra por 30 s com uma baquete de vidro. O conteúdo foi deixado em repouso por 10 min e, em seguida, centrifugou-se a amostra a $2.300 \mathrm{rpm}$ por $25 \mathrm{~min}$. Decantou-se e esgotouse o sobrenadante. O tubo foi colocado inclinado para baixo (ângulo de $15^{\circ}$ a $20^{\circ}$ ), numa estufa a $50^{\circ} \mathrm{C}$, com circulação de ar, durante 25 min. Esfriou-se o tubo em dessecador e pesou-se. A absorção de água foi calculada em relação a $100 \mathrm{~g}$ de amostra.

\subsection{5 - Propriedades espumantes}

As propriedades espumantes abrangem a expansão de espuma e a estabilidade de espuma, as quais foram determinadas, de acordo com WANG, CABALLERO-CÓRDOBA \& SGARBIERI [18]. O cálculo da expansão de espuma, expresso em percentagens, foi feito, conforme o método descrito por LAWHON, CATER \& MATIL [10] (Equação 1):

$\%$ Expansão de espuma $=\frac{\text { Vol. após agitação }- \text { vol. antes da agitação }}{\text { Vol. antes da agitação }} \times 100$

O volume de espuma foi calculado, considerando-se como $100 \%$ o volume de espuma no tempo zero. A percentagem de sinérese, que é o inverso da estabilidade de espuma, foi calculada segundo o método descrito por SATTERLEE, BEMBERS \& KENDRICK [13].

\subsection{6 - Análise estatística}

Foi usado o Delineamento Inteiramente Casualizado (DIC) nas análises, e os dados obtidos foram submetidos às análises de variância, com posterior comparação das diferenças entre as médias pelo teste de Tukey a $5 \%$ de probabilidade. Todas as análises estatísticas foram realizadas conforme os métodos descritos por PIMENTEL-GOMES [12].

\section{3 - RESULTADOS E DISCUSSÃO}

A Tabela 1 apresenta, em base seca, a composição centesimal aproximada da farinha de trigo, dos grãos de soja integrais e decorticados e da farinha mista crua de trigo e soja (90:10).

Através da Tabela 1, observa-se que a composição centesimal aproximada obtida para a farinha de trigo foi semelhante àquela encontrada por LEITÃO, GONÇALVES \& VITTI [11]. O teor de cinzas dos grãos de soja decorticados foi semelhante, e os teores de proteína bruta e extrato etéreo foram maiores do que aqueles dos grãos de soja integrais. O alto teor de fibra bruta da soja integral indica que a casca contém grande quantidade deste componente. A soja apresentou maiores teores de proteína bruta, extrato etéreo, cinzas e fibra bruta, do 
que quando comparada à farinha de trigo. Uma vez que a soja não contém amido, a farinha mista crua de trigo e soja, na proporção de 90:10, apresentou menor teor de carboidratos, em relação à farinha de trigo.

TABELA 1 - Composição centesimal aproximada (\% base seca) da farinha de trigo, dos grãos de soja integrais e decorticados, e da farinha mista crua de trigo e soja (90:10)

\begin{tabular}{|c|c|c|c|c|}
\hline $\begin{array}{l}\text { Composição } \\
(\%)\end{array}$ & $\begin{array}{l}\text { Farinha } \\
\text { de trigo }\end{array}$ & $\begin{array}{c}\text { Soja } \\
\text { integral }\end{array}$ & $\begin{array}{c}\text { Soja } \\
\text { decorticada }\end{array}$ & $\begin{array}{c}\text { Farinha } \\
\text { mista } \\
\text { crua de } \\
\text { trigo e } \\
\text { soja }\end{array}$ \\
\hline Proteína bruta & 13,06 & 42,04 & 45,90 & 16,08 \\
\hline Extrato etéreo & 1,25 & 18,63 & 20,62 & 3,19 \\
\hline Cinzas & 0,59 & 4,60 & 4,52 & 0,98 \\
\hline Fibra bruta & 0,65 & 6,56 & 4,48 & 1,05 \\
\hline Carboidratos $^{(1)}$ & 84,45 & 28,17 & 24,48 & 78,70 \\
\hline
\end{tabular}

A Tabela 2 mostra absorção de água (AA) das farinhas de trigo e soja (90:10) extrusadas por diferentes velocidades de rotação de parafuso (VRP), em diferentes combinações de umidade e temperaturas do canhão (TC) nas zonas 2 e 3 .

Nota-se que, no nível de $23 \%$ de umidade, a AA das farinhas extrusadas de trigo e soja (90:10) aumentou, à medida que se elevavam a VRP ( 120 a $180 \mathrm{rpm}$ ) e a TC (80 a $100^{\circ} \mathrm{C}$ ) .Contudo, nos níveis de 26 e $29 \%$ de umidade, o aumento da VRP até $150 \mathrm{rpm}$ resultou num aumento de AA a 80 e $90^{\circ} \mathrm{C}$, porém, a $100^{\circ} \mathrm{C}$, a AA diminuiu com o aumento da VRP. E para a mesma VRP, verifica-se que o aumento da TC até $90^{\circ} \mathrm{C}$ causou um aumento de AA, exceto para VRP de $120 \mathrm{rpm}$ em 26\% de umidade, na qual houve um aumento continuo. De modo geral, o aumento de umidade (23 a 29\%) proporcionou também maior AA.

O aumento da AA em função da elevação da TC, ocorrido neste presente trabalho, foi semelhante ao encontrado por GONZÁLEZ et al. [4] e GUTIÉRREZ \& GOMEZ [5], os quais constataram que a AA está relacionada com a capacidade de intumescimento dos grânulos de amido, enquanto se mantém a sua morfologia.

Além da TC, o aumento da VRP e do nível de umidade deste presente trabalho, pode também ter contribuído para maior AA, desde que o aumento dos parâmetros acima citados não causasse rompimento dos grânulos de amido. De acordo com GONZÁLEZ et al. [4], a AA do amido, nos níveis de umidade entre 25 e 35\%, aumentou com a elevação da TC até $140^{\circ} \mathrm{C}$, além da qual, passou a diminuir, por causa da alteração da integridade dos grânulos. A redução de AA do amido de milho extrusado com o aumento da $\mathrm{TC}\left(80\right.$ a $160^{\circ} \mathrm{C}$ ) foi também verificada por TANG \& DING [16].

Acredita-se, portanto, que a AA dependa não só da disponibilidade de grupos hidrofílicos, que ligam as moléculas de água, mas também da capacidade formadora de gel de macromoléculas, como amido gelatinizado. $\mathrm{O}$

TABELA 2 - Absorção de água (AA) das farinhas de trigo e soja (90:10) extrusadas por diferentes velocidades de rotação de parafuso (VRP), em diferentes combinações de umidade e temperaturas do canhão (TC) nas zonas 2 e $3^{(1)}$

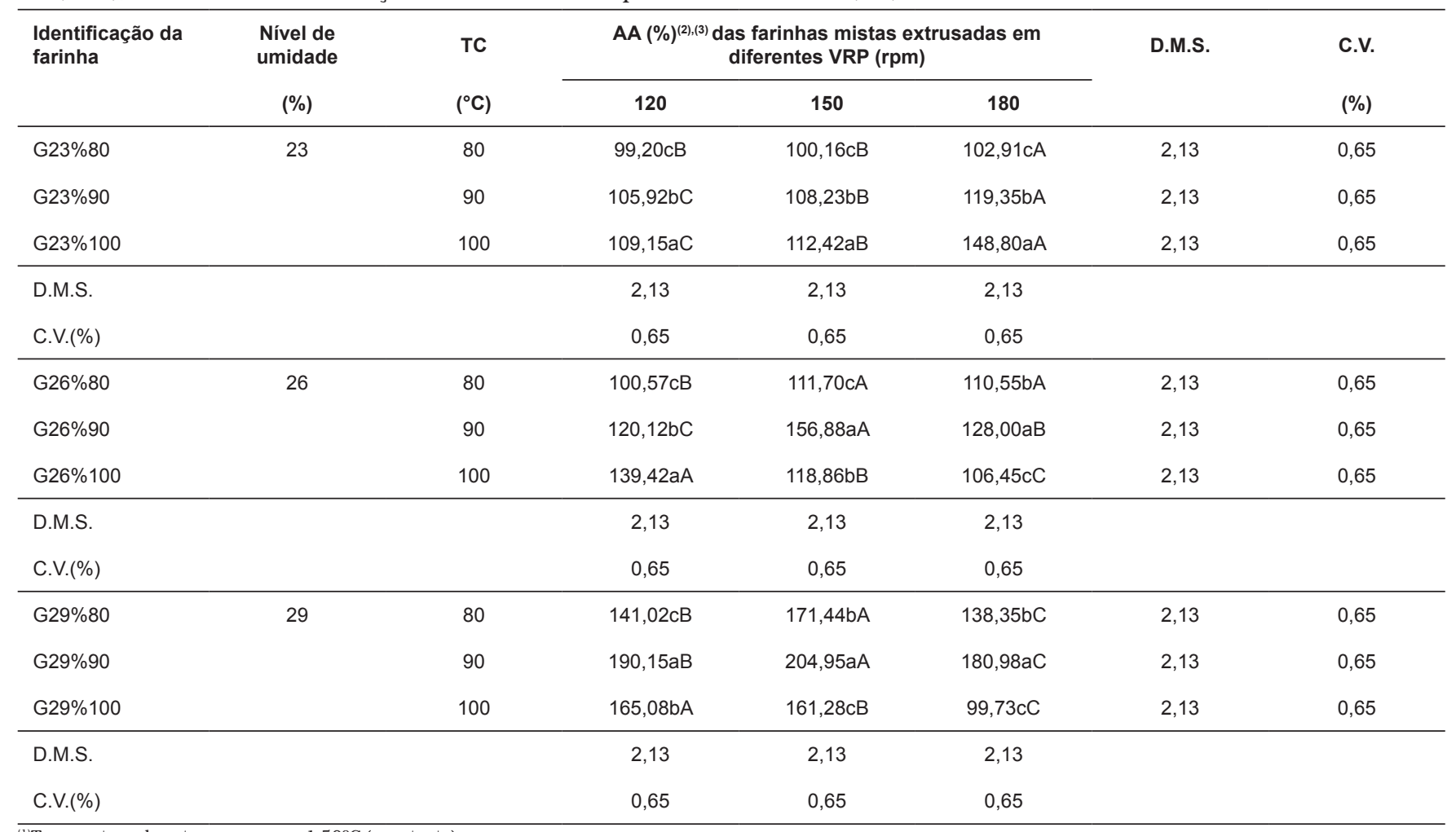

${ }^{(1)}$ Temperatura do extrusor na zona $1: 50^{\circ} \mathrm{C}$ (constante)

${ }^{(2)}$ As médias seguidas de letras diferentes, maiúscula nas linhas e minúscula nas colunas, diferem estatisticamente entre si pelo teste de Tukey a $5 \%$ de probabilidade ${ }^{(3)} \mathrm{AA}$ da farinha de trigo crua (controle) e da farinha mista crua (controle) foram 56,56 e $65,39 \%$, respectivamente 
aumento da VRP resulta, no processo de extrusão, em maior atrito entre as moléculas, gerando maior calor, o que por conseqüência, favorece a gelatinização do amido. A elevação da TC e o aumento do nível de umidade intensificam também o processo de gelatinização. Entretanto, o excesso de calor pode causar a hidrólise do amido, reduzindo a sua capacidade formadora de gel e diminuindo a sua AA.

A AA é uma propriedade relevante para aplicações em produtos cárneos, pães e bolos; valores altos de AA são importantes para ajudar a manter a umidade dos mesmos [7]. As farinhas extrusadas de trigo e soja (90:10) deste presente trabalho, mostraram valores de AA maiores do que aqueles obtidos para farinha de trigo crua (controle) e farinha mista crua (controle). Desta maneira, as farinhas extrusadas estudadas podem ser desejáveis nos produtos cárneos e de panificação, pois permite a adição de mais água à massa, melhorando suas características de manuseio.

Expansão de espuma (EE) das farinhas de trigo e soja (90:10) extrusadas por diferentes VRP, em diferentes combinações de umidade e TC nas zonas 2 e 3, está apresentada na Tabela 3 e as Tabelas 4 e 5 mostram, respectivamente, o volume de espuma (VE) e a sinérese após diferentes tempos, das farinhas de trigo e soja (90:10) extrusadas por diferentes VRP, em diferentes combinações de umidade e TC nas zonas 2 e 3.

Pela Tabela 3 , observa-se que, no nível de $23 \%$ de umidade, houve um aumento na EE quando se elevaram a VRP (120 a $180 \mathrm{rpm})$ e a TC $\left(80\right.$ a $\left.100^{\circ} \mathrm{C}\right)$. No entanto, nos níveis de 26 e $29 \%$ de umidade, a $\mathrm{EE}$ aumentou com o aumento da VRP em $80^{\circ} \mathrm{C}$, porém em 90 e $100^{\circ} \mathrm{C}$, os maiores valores foram verificados em $150 \mathrm{rpm}$. Exceto para VRP de $180 \mathrm{rpm}$, EE aumentou com o aumento da TC e do nível de umidade (23 a 29\%).

Através das Tabelas 4 e 5, verifica-se que, com o aumento da VRP (120 a $180 \mathrm{rpm}$ ) e da TC $\left(80\right.$ a $\left.100^{\circ} \mathrm{C}\right)$, ocorreu um aumento no VE e uma diminuição na sinérese após 30, 60 e 120 min, no nível de $23 \%$ de umidade. Para níveis de 26 e $29 \%$ de umidade, os maiores valores do VE e os menores valores da sinérese após 30, 60 e $120 \mathrm{~min}$, foram obtidos em $150 \mathrm{rpm}$ a $90^{\circ} \mathrm{C}$. O aumento do nível de umidade (23 a 29\%) nem sempre causou aumento no VE e diminuição na sinérese.

A EE está muito relacionada com a concentração de proteínas, sendo necessárias proteínas de cadeias flexíveis, pobres em estruturas secundárias e terciárias que se adaptem rapidamente na interfase ar-líquido. Além disso, é preciso que estas proteínas tenham a possibilidade de formar ligações hidrofóbicas na sua superfície. A estabilidade de espuma se relaciona com a qualidade da proteína, sendo necessário que se formem películas coesivas, elásticas, contínuas e impermeáveis ao ar [3].

A estabilidade de espuma nem sempre se correlaciona com a EE. Alguns produtos de soja apresentam baixa estabilidade, apesar de ter alta EE, enquanto que outros mostram a estabilidade proporcional à EE. A estabilidade de espuma se correlaciona altamente com o grau de desnaturação da proteína [20].

TABELA 3 - Expansão de espuma (EE) das farinhas de trigo e soja (90:10) extrusadas por diferentes velocidades de rotação de parafuso (VRP), em diferentes combinações de umidade e temperaturas do canhão (TC) nas zonas 2 e $3^{(1)}$

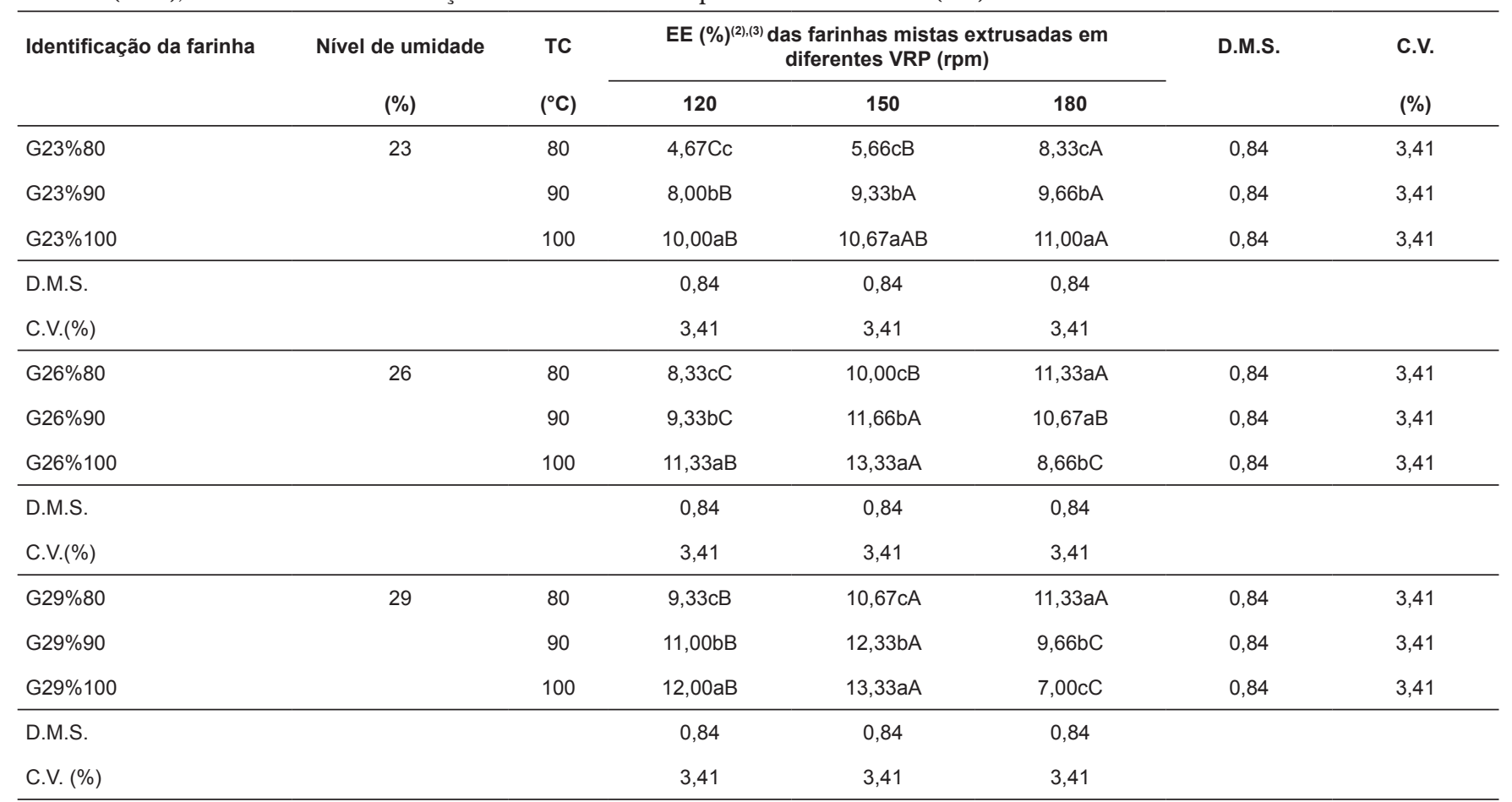

(1) Temperatura do extrusor na zona $1: 50^{\circ} \mathrm{C}$ (constante)

${ }^{(2)}$ As médias seguidas de letras diferentes, maiúscula nas linhas e minúscula nas colunas, diferem estatisticamente entre si pelo teste de Tukey a $5 \%$ de probabilidade ${ }^{(3)} \mathrm{EE}$ da farinha de trigo crua (controle) e da farinha mista crua (controle) foram 45,33 e $38,66 \%$, respectivamente 
TABELA 4 - Volume de espuma (VE) após diferentes tempos, das farinhas de trigo e soja (90:10) extrusadas por diferentes velocidades de rotação de parafuso (VRP), em diferentes combinações de umidade e temperaturas do canhão (TC) nas zonas 2 e $3^{(1)}$

\begin{tabular}{|c|c|c|c|c|c|c|c|c|c|c|c|c|c|c|c|c|c|}
\hline \multirow{2}{*}{$\begin{array}{l}\text { Identificação } \\
\text { da farinha }\end{array}$} & \multirow{2}{*}{$\begin{array}{c}\begin{array}{c}\text { Nível } \\
\text { de } \\
\text { umidade }\end{array} \\
(\%)\end{array}$} & \multirow{2}{*}{ TC } & \multicolumn{15}{|c|}{ VE $(\%)^{(2)}$ após diferentes tempos $(\mathrm{min})$ das farinhas mistas extrusadas em diferentes VRP (rpm) } \\
\hline & & & \multicolumn{3}{|c|}{$30 \min ^{(3)}$} & D.M.S. & $\begin{array}{l}\text { C.V. } \\
(\%)\end{array}$ & \multicolumn{3}{|c|}{$60 \min ^{(4)}$} & D.M.S. & $\begin{array}{l}\text { C.V. } \\
(\%)\end{array}$ & \multicolumn{3}{|c|}{$120 \min ^{(5)}$} & D.M.S. & $\begin{array}{l}\text { C.V. } \\
(\%)\end{array}$ \\
\hline G23\%80 & 23 & 80 & $85,71 \mathrm{cC}$ & $88,99 \mathrm{bB}$ & $91,28 \mathrm{bA}$ & 1,54 & 0,67 & $77,50 \mathrm{bB}$ & $80,00 \mathrm{cB}$ & $90,91 \mathrm{bA}$ & 2,83 & 1,29 & $72,50 \mathrm{bB}$ & $75,00 \mathrm{cB}$ & $80,00 \mathrm{cA}$ & 2,74 & 1,39 \\
\hline G23\%90 & & 90 & $88,89 \mathrm{bB}$ & $90,27 \mathrm{bAB}$ & $91,66 \mathrm{bA}$ & 1,54 & 0,67 & $80,00 \mathrm{bB}$ & $89,90 \mathrm{bA}$ & $91,66 \mathrm{bA}$ & 2,83 & 1,29 & $75,00 \mathrm{bC}$ & $80,00 \mathrm{bB}$ & $84,52 \mathrm{bA}$ & 2,74 & 1,39 \\
\hline D.M.S. & & & 1,54 & 1,54 & 1,54 & & & 2,83 & 2,83 & 2,83 & & & 2,74 & 2,74 & 2,74 & & \\
\hline C.V. ( \%) & & & 0,67 & 0,67 & 0,67 & & & 1,29 & 1,29 & 1,29 & & & 1,39 & 1,39 & 1,39 & & \\
\hline G26\%80 & 26 & 80 & $87,30 \mathrm{cB}$ & $91,28 \mathrm{bA}$ & $91,98 \mathrm{aA}$ & 1,54 & 0,67 & $87,30 \mathrm{cB}$ & $91,28 \mathrm{bA}$ & $91,98 a A$ & 2,83 & 1,29 & $80,00 \mathrm{cB}$ & $84,52 \mathrm{bA}$ & $85,71 \mathrm{aA}$ & 2,74 & 1,39 \\
\hline G26\%90 & & 90 & $90,91 \mathrm{bB}$ & $100,00 a A$ & $91,28 \mathrm{aB}$ & 1,54 & 0,67 & $90,91 \mathrm{bB}$ & $100,00 a A$ & $91,28 \mathrm{aB}$ & 2,83 & 1,29 & $83,33 \mathrm{bB}$ & $94,44 \mathrm{aA}$ & $85,71 \mathrm{aB}$ & 2,74 & 1,39 \\
\hline G26\%100 & & 100 & $95,00 \mathrm{aB}$ & $100,00 a A$ & $88,89 \mathrm{bC}$ & 1,54 & 0,67 & $95,00 \mathrm{aB}$ & $100,00 \mathrm{aA}$ & $85,71 \mathrm{bC}$ & 2,83 & 1,29 & $88,89 a \mathrm{~B}$ & $91,98 \mathrm{aA}$ & $80,00 \mathrm{bC}$ & 2,74 & 1,39 \\
\hline G29\%90 & & 90 & $94,27 \mathrm{bB}$ & $100,00 \mathrm{aA}$ & $88,89 b \mathrm{~b}$ & 1,54 & 0,67 & $91,66 \mathrm{aA}$ & $94,44 \mathrm{aA}$ & $80,00 \mathrm{bB}$ & 2,83 & 1,29 & $75,00 \mathrm{aB}$ & $80,00 a A$ & $66,66 \mathrm{bC}$ & 2,74 & 1,39 \\
\hline G29\%100 & & 1001 & $100,00 \mathrm{aA}$ & $100,00 \mathrm{aA}$ & $81,81 \mathrm{cB}$ & 1,54 & 0,67 & $80,00 \mathrm{bA}$ & $77,50 \mathrm{cA}$ & $70,00 \mathrm{cB}$ & 2,83 & 1,29 & $70,00 \mathrm{bA}$ & $66,66 \mathrm{bB}$ & $54,54 \mathrm{cC}$ & 2,74 & 1,39 \\
\hline D.M.S. & & & 1,54 & 1,54 & 1,54 & & & 2,83 & 2,83 & 2,83 & & & 2,74 & 2,74 & 2,74 & & \\
\hline C.V. ( \%) & & & 0,67 & 0,67 & 0,67 & & & 1,29 & 1,29 & 1,29 & & & 1,39 & 1,39 & 1,39 & & \\
\hline
\end{tabular}

${ }^{(1)}$ Temperatura do extrusor na zona $1: 50^{\circ} \mathrm{C}$ (constante)

${ }^{(2)}$ As médias seguidas de letras diferentes, maiúscula nas linhas e minúscula nas colunas, diferem estatisticamente entre si pelo teste de Tukey a $5 \%$ de probabilidade

${ }^{(3)} \mathrm{VE}$ da farinha de trigo crua (controle) e da farinha mista crua (controle) após $30 \mathrm{~min}$, foram 32,61 e 46,67\%, respectivamente

${ }^{(4)} \mathrm{VE}$ da farinha de trigo crua (controle) e da farinha mista crua (controle) após $60 \mathrm{~min}$, foram 9,76 e 9,37\%, respectivamente

${ }^{(5)} \mathrm{VE}$ da farinha de trigo crua (controle) e da farinha mista crua (controle) após $120 \mathrm{~min}$, foram 6,52 e 6,25\%, respectivamente

TABELA 5 - Sinérese após diferentes tempos, das farinhas de trigo e soja (90:10) extrusadas por diferentes velocidades de rotação de parafuso (VRP), em diferentes combinações de umidade e temperaturas do canhão (TC) nas zonas 2 e $3^{(1)}$

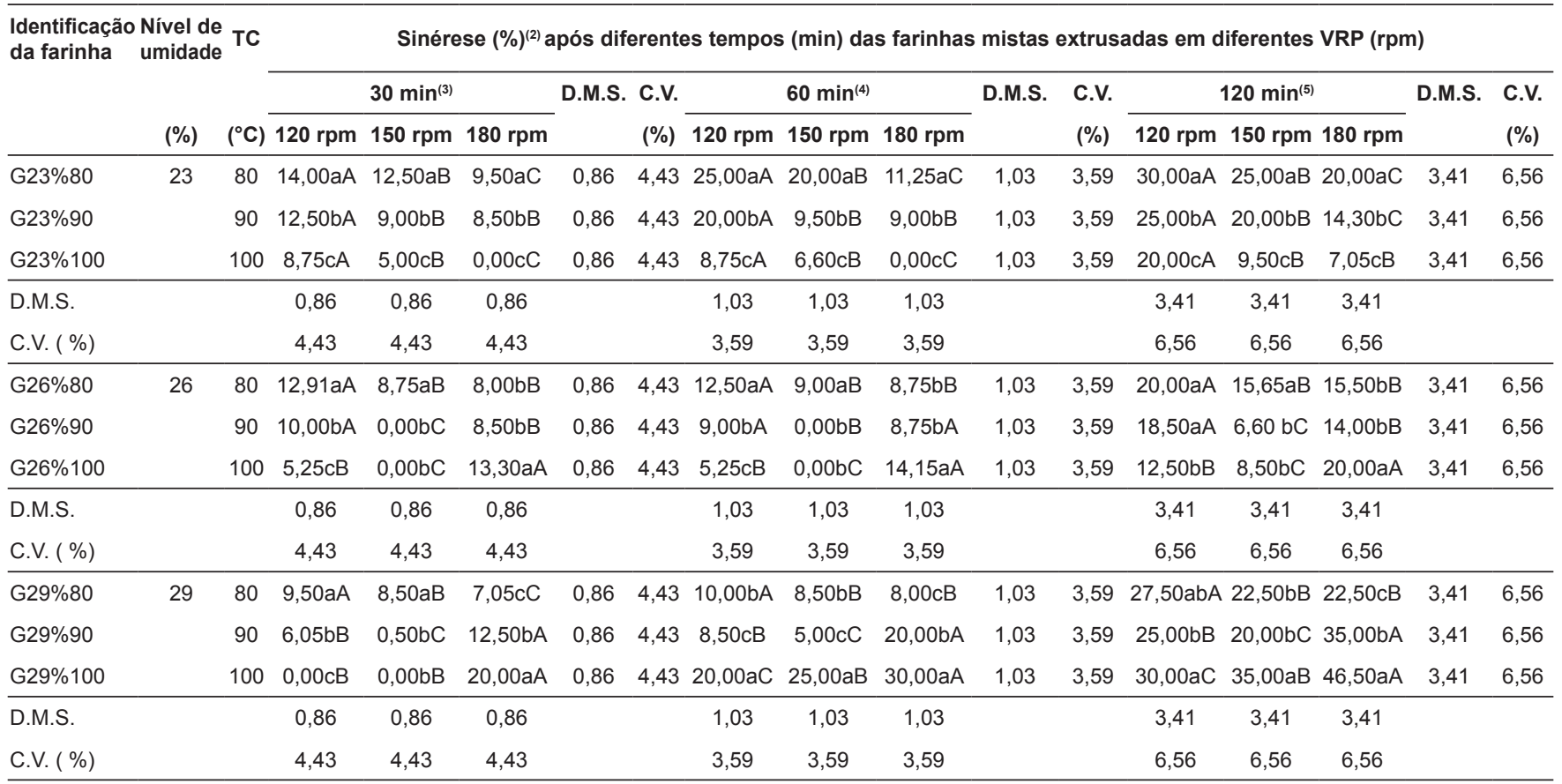

${ }^{(1)}$ Temperatura do extrusor na zona $1: 50^{\circ} \mathrm{C}$ (constante)
${ }^{(2)} \mathrm{As}$ médias seguidas de letras diferentes, maiúscula nas linhas e minúscula nas colunas, diferem estatisticamente entre si pelo teste de Tukey a $5 \%$ de probabilidade

${ }^{(2)}$ As médias seguidas de letras diferentes, maiúscula nas linhas e minúscula nas colunas, diferem estatisticamente entre si pelo teste de
${ }^{(3)}$ Sinérese da farinha de trigo crua (controle) e da farinha mista crua (controle) após 30 min, foram 68,75 e 55,55\%, respectivamente

${ }^{(4)}$ Sinérese da farinha de trigo crua (controle) e da farinha mista crua (controle) após 60 min, foram 90,25 e 90,89\%, respectivamente

${ }^{(5)}$ Sinérese da farinha de trigo crua (controle) e da farinha mista crua (controle) após 120 min, foram 94,55 e 94,75\%, respectivamente 
Verifica-se, pelo presente trabalho, que houve uma correlação positiva entre a EE e a estabilidade de espuma das farinhas de trigo e soja (90:10) extrusadas nos níveis de 23 e $26 \%$ de umidade, porém não no nível de $29 \%$ de umidade. No processo de extrusão, o aumento da VRP e da TC pode ter contribuído para maior desnaturação da proteína, o que pode ter favorecido ou desfavorecido a formação de películas coesivas, elásticas, contínuas e impermeáveis ao ar, dependendo do nível de umidade aplicado. De maneira geral, as farinhas extrusadas mostraram melhor estabilidade de espuma do que as farinhas cruas (controles).

A EE e a estabilidade de espuma são importantes em produtos de forno, merengues e coberturas de bolos, por ajudarem na incorporação de ar [7]. A farinha de trigo crua (controle) e a farinha mista crua (controle), apesar de ter apresentado excelente EE, não mostraram estabilidade de espuma tão boa, quanto às farinhas extrusadas de trigo e soja (90:10) estudadas, após $120 \mathrm{~min}$. Este fato sugere que, estas farinhas extrusadas, sejam melhores do que as de controle para o uso em produtos de forno, onde a estabilidade da incorporação de ar ajuda a manter boa textura da massa.

\section{4 - CONCLUSÕES}

- A absorção de água das farinhas extrusadas de trigo e soja (90:10) aumenta, com o aumento da velocidade de rotação de parafuso e temperatura do canhão, em 23\% de umidade. Contudo, em 26 e $29 \%$ de umidade, o maior valor desta é obtido em $150 \mathrm{rpm}$ a $90^{\circ} \mathrm{C}$.

- A expansão de espuma e a estabilidade de espuma aumentam, à medida que se aumentam a velocidade de rotação do parafuso e temperatura do canhão, em $23 \%$ de umidade.

- $\quad$ Em 26 e 29\% de umidade, a expansão de espuma aumenta, com o aumento da velocidade de rotação de parafuso em $80^{\circ} \mathrm{C}$, e em 90 e $100^{\circ} \mathrm{C}$, os maiores valores são encontrados em $150 \mathrm{rpm}$. Exceto para 180 rpm, a expansão de espuma aumenta, com o aumento da temperatura do canhão. A maior estabilidade de espuma é verificada em $150 \mathrm{rpm}$ a $90^{\circ} \mathrm{C}$.

- A farinha de trigo e soja (90:10) com 23\% de umidade, extrusada em $180 \mathrm{rpm}$ a $100^{\circ} \mathrm{C}$, bem como aquela com $26 \%$ de umidade, extrusada em 150 rpm a $90^{\circ} \mathrm{C}$, são recomendadas para o uso em bolo esponja, por ter apresentado boa absorção de água e boas propriedades espumantes, especialmente, excelente estabilidade de espuma.

\section{5 - REFERÊNCIAS BIBLIOGRÁFICAS}

[1] AMERICAN ASSOCIATION OF CEREAL CHEMISTS. Approved methods of the American Association of Cereal Chemists. $9^{\text {th }}$ ed. St. Paul: AACC, 1995, 2 v.

[2] CABAllERO-CÓRDOBA, G.M.; WANG, S.H.;
SGARBIERI, V.C. Características nutricionais e sensoriais de sopa cremosa semi-instantânea à base de farinhas de trigo e soja desengordurada. Pesquisa Agropecuária Brasileira, Brasília, v. 29, n. 7, p. 1.137-1.143, 1994.

[3] Cheftel, J.C.; CUQ, J.L.; LORIENT, D. Proteínas alimentarias, Zaragoza: Acribia, 1989, 346 p.

[4] GONZÁLEZ, R.J.; TORRES, R.L.; DE GREEF, D.M.; GORDO, N.A. Evaluación de almidón de maíz precocido por extrusión-cocción. Revista Agroquímica y Tecnologia de Alimentos, Valéncia, v. 26, n. 4, p. 552-564, 1986.

[5] GUTIÉRREZ, M.V.G. de; GÓMEZ, M.H. Modelo para la extrusión de mezclas maíz: soja (70:30). Archivos Latinoamericanos de Nutrición, Caracas, v. 37, n. 3, p. 494-502, 1987.

[6] HORVÁTH, E.; PETRES, J.; GELENCSÉR, É; CZUKOR, B. Effect of extrusion temperature on physico-chemical properties and biological value of soybean-protein. Acta Alimentaria, Budapest, v. 18, n. 2 , p. 199-211, 1989.

[7] JAMES, C.; SLOAN, S. Functional properties of edible rice bran in model systems. Journal of Food Science, Chicago, v. 49, n. 1, p. 310-311, 1984.

[8] KAMER, J.H. van de; GINKEL, L. van. Rapid determination of crude fiber in cereals. Cereal Chemistry, St. Paul, v. 29, n. 4, p. 239-251, 1952.

[9] KIM, J.C.; ROTTIER, W. Modification of aestivum wheat semolina by extrusion. Cereal Foods World, St. Paul, v. 24, n. 2 , p. $62-65,1980$.

[10] LAWHON, J.T.; CATER, C.M.; MATIL, K.F. A comparative study of the whipping potential of an extract from several oilseed flours. Cereal Science Today, St. Paul, v. 17 , n. 4, p. 240-294, 1972.

[11] LEITÃO, R.F.F.; GONÇALVES, J.R.; VITTI, P. Utilização da alta temperatura na secagem de macarrão. Coletânea Ital, Campinas, v. 19, n. 2, p. 186-195, 1989.

[12] PIMENTEL GOMES, F. Curso de estatística experimental, 13 ${ }^{\mathrm{a}}$ ed. São Paulo: Nobel, 1991, 468 p.

[13] SATTERLEE, L.D.; BEMBERS, M.; KENDRICK, J.G. Functional properties of the great northern bean (Phaseolus vulgaris) protein isolate. Journal of Food Science, Chicago, v. 40, n. 1, p. 81-84, 1975.

[14] SGABIERI, V.C. Proteínas em alimentos protéico: propriedades, degradações, modificações, $1^{\text {a }}$ ed. São Paulo: Livraria Varela Ltda., 1996, 517 p.

[15] SOSULSKI, F.W. The centrifuge method for determining flour absorption in hard red spring wheats. Cereal Chemistry, St. Paul, v.39, n. 4, p. 344-350, 1962.

[16] TANG, J.; DING, X.L. Relationship between functional properties and macromolecular modifications of extruded corn starch. Cereal Chemistry, St. Paul, v. 71, n. 4, p. 364-369, 1994.

[17] WANG, S.H.; ASCHERI, J.L.R.; OLIVEIRA, M.F.; FERNANDES, M.S. Características tecnológicas y sensoriales de harinas de arroz-soya (70:30) extruídas para uso como papilla instantánea. Alimentaria, Madrid, v. 38, n. 324, p. 77-84, 2001.

[18] WANG, S.H.; CABALLERO-CÓRDOBA, G.M.; SGARBIERI, V.C. Propriedades funcionais de misturas de farinhas de trigo e soja desengordurada, pré-tratadas por microondas. Ciência e Tecnologia de Alimentos, 
Campinas, v. 12, n. 1, p. 14-25, 1992.

[19] WANG, S.H.; OLIVEIRA, M.F.; COSTA, P.S.; ASCHERI, J.L.R.; ROSA, A.G. Farinhas de trigo e soja pré-cozidas por extrusão para massas de pizza. Pesquisa Agropecuária Brasileira, Brasília, v. 40, n. 4, p. 389-395, 2005.
[20] YASUMATSU, K.; SAWADA, K. MORITAKA, S.; MISAKI, M.; TODA, J.; WADA, T.; ISHII, K. Whipping and emulsifying properties of soybean products. Agricultural and Biological Chemistry, Tokyo, v. 36, n. 5, p. 719727,1972 . 